\title{
Physical and mental health aspects of elderly in social care in Poland
}

This article was published in the following Dove Press journal:

Clinical Interventions in Aging

21 October 2014

Number of times this article has been viewed

\section{Dorota Dobrzyn-Matusiak' \\ Czesław Marcisz ${ }^{2}$}

Ewelina Bąk ${ }^{3}$

Halina Kulik'

Ewa Marcisz ${ }^{4}$

'Department of Nursing Propaedeutics, ${ }^{2}$ Department of Gerontology and Geriatric Nursing, School of Health Care, Medical University of Silesia, Katowice, Poland; ${ }^{3}$ Faculty of Health Sciences, University of Bielsko-Biała, Bielsko-Biała, Poland; ${ }^{4}$ Department of Anxiety Disorders, Hospital of Ministry of Internal Affairs, Katowice, Poland
Correspondence: Ewelina Bak Faculty of Health Sciences, University of Bielsko-Biała, ul Willowa 2, 43-300 Bielsko-Biała, Poland

Tel +48338279167

Email ewelina.bak76@wp.pl
Background: The objective of the study was to evaluate health aspects in elderly individuals in social, institutional, and home care in Poland.

Methods: A total of 300 elderly individuals in care in Poland were included in the study. The subjects were divided into three groups: residents of long-term care institutions (group I), residents of adult day-care homes (group II), and community-dwelling subjects (group III). Each group consisted of 100 subjects. Questionnaires evaluating the following physical and mental dimensions of health were used: SF-36 Health Survey, basic activities of daily living, instrumental activities of daily living, Geriatric Depression Scale, and Mini-mental state examination.

Results: It was found that the health aspects of the elderly varied depending on whether care was provided in an institutionalized or a home environment, and the lowest health status was found in the elderly receiving in-home care. Furthermore, home-based elderly indicated significant limitations in performing basic activities of daily living and instrumental activities of daily living, as well as a higher prevalence of depression and cognitive impairment.

Conclusion: The elderly in long-term institutionalized care, both in a residential home and adult day-care homes, were characterized by a better physical and mental health status than those receiving in-home care. It seemed that worse health status, including the more frequent depression occurrence and cognitive function disorders in the elderly using the nursing care at their homes, was related to their multimorbidity, loneliness, and too-short duration of the care during the day.

Keywords: social institutions, health status, activities of daily living, depression, cognitive function

\section{Introduction}

The aging process is associated with heterogeneity and interindividual variability, depending on biological, psychological, social, and economic factors. ${ }^{1}$

The rate of growth of the elderly population (persons aged 65 years and above) in the world is on a continued increase..$^{2-4}$ Demographic projections indicate that the proportion of elderly individuals within the general population in Poland will reach $17.4 \%$ in the year 2020, whereas in the year 2001 it did not exceed $12.5 \% .^{5}$

Advancing age brings a natural gradual weakening of functional capacity and a progressive decrease in physiologic reserve capacity leading to permanent deficits of physical function and psychomotor efficiency. The effects of aging and pathology that frequently accompanies aging lead to a loss of autonomy and functional independence for older persons. In addition, it reduces their quality of life and requires provision for long-term care. , $^{6}$

In Poland, informal care was traditionally provided in the family setting. However, social and economic changes have affected the role of the family as the main care 
providers. In an era of intense transformation of civilization, the provision of informal care for a dependent relative, particularly for an impaired elderly person, frequently exceeds the physical, mental, and economic potential of family caregivers. Increasingly, institutional structures providing care for the elderly are used. There are such institutions as residential homes, nursing and care homes, and adult daycare homes which address the needs and expectations of the elderly regarding specialized care services and are met with increasing confidence among care recipients and their families. $^{8}$

At the elderly age, there is an increase in the numbers of dementia patients who require care to provide them with a better health status. There is a shortage of comparative studies regarding health status in relation to dementia and depression among the elderly in residential homes and home care in the literature. The studies conducted in Finland showed that health-related quality of life seemed to be lower in elderly living in residential care homes than in the noninstitutionalized population. ${ }^{9}$ However, the findings of the study conducted in Canada in the elderly suggest that quality of life for persons with middle- to late-stage dementia is the same or better in a purpose-built and staffed specialized-care facility than in traditional institutional settings. ${ }^{10}$

In the present study, for analytical reasons as well as for practical application, the classification of the elderly individuals' care has been based on the following criteria: the length of time for which care has been provided and the setting of care provision (institutional care versus home-based care). According to the adopted classification, the following types of elderly care have been distinguished:

1. Institutional long-term care provided by residential care facilities (long-term stay in a residential home by the elderly who require 24-hour inpatient care).

2. Assisted care provided by adult day-care homes (care and services provided to elderly adults who require supervision during the day and in-home care in the evening and at night).

3. Home-based care (care and services provided to the elderly at their place of residence).

Social care, and particularly the range of care-service provision, is the important preventive action improving health status and quality of life in the elderly, especially those affected by multiple diseases limiting physical and mental efficiency. In the studies on social care, the health aspects of elderly have not been comprehensively considered. In particular, studies of social care provided in Poland, which is why the study on evaluation of the health aspects of elderly individuals in social, institutional, and home care in Poland has been conducted.

\section{Material and methods}

A cross-sectional study was conducted in 300 elderly individuals of southern Poland, including 178 women and 122 men aged 65 years and above. The subjects were eligible for the study if they had received care for a minimum of 3 months; if they showed no major physical dysfunctions and cognitive disorders that would affect their ability to complete the questionnaire; and they completed a written informed consent. For analysis of this study, the subjects were divided into three groups of randomly selected persons. Each group consisted of 100 subjects. The characteristics of the groups are presented below.

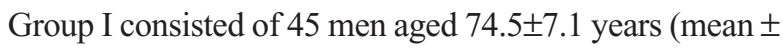
standard deviation) and 55 women aged $79.4 \pm 7.5$ years. According to the aforementioned selection criteria, those persons were randomly selected from 197 possible subjects. The subjects were inhabitants of three randomly selected residential homes where they received permanent day and night care.

Group II encompassed 40 men aged $72.3 \pm 6.8$ years and 60 women aged $71.4 \pm 5.7$ years, selected according to the selection criteria from 127 persons, who received care in four randomly selected adult day-care homes. The subjects were provided care on an hourly basis, ie, 10 hours daily, 5 days a week. For the rest of the time they stayed at their place of residence. The subjects received both institutional and in-home care. In this group, 82 individuals lived alone, nine lived with a spouse, and nine lived with their children and their family.

Group III was made up of community-dwelling elderly individuals under the social assistance system, ie, care services were provided by community nurses at the subjects' place of residence for 3 hours daily. The randomly selected group included 37 men aged $75.5 \pm 8.3$ years and 63 women aged $77.7 \pm 7.5$ years. Those persons were selected according to the selection criteria from the 141 individuals using this type of care provision. Eighty-two subjects lived alone, 14 subjects lived with immediate family (with their son's or daughter's family, grandchildren, siblings), three persons lived with their spouses, and one individual lived with a caregiver.

All groups were similar to each other with regard to education level of the subjects.

The study was approved by the Bioethical Commission of the Medical University of Silesia. The data were collected by means of a questionnaire. The following measures were used. 
The health status was assessed with the questionnaire SF-36v2 Health Survey Polish version. The SF-36v2 measures the physical and mental health status in ten health dimensions: physical functioning, role physical, bodily pain, general health, vitality, social functioning, mental health, role emotional, physical component summary (PCS), and mental component summary (MCS).${ }^{11}$ Every health dimension was determined by coding, summing up, and converting the responses into numerical values in the scale ranging from 0 (the lowest level of the health status) to 100 (the highest level of the health care status). Permission to the use of SF-36 was obtained (license number F1-111008-38768).

Activities of daily living (ADL) were assessed with two evaluation instruments: the Katz scale to assess the ability to perform basic ADL and the Lawton scale to assess the ability to perform instrumental ADL (IADL). ${ }^{12,13}$

The 30-item Geriatric Depression Scale (GDS) was used to measure self-rated depressive symptoms..$^{14}$ The obtained results indicate the lack of depression ( $0-9$ points), mild depression (10-19), and severe depression (>19).

The Mini-mental state examination (MMSE) was used to assess cognitive function. ${ }^{15}$ In the 30 -item scale, a score below 24 points shows the presence of cognitive-function impairment, which indicates dementia.

The studies identified an internal consistency index of Cronbach's $\alpha ;{ }^{16}$ it ranged from 0.73 to 0.87 across domains for the SF-36v2 Health Survey and was 0.84 for GDS.

All analyses were performed with STATISTICA 7.1 PL application software and the Microsoft Excel spreadsheet application. The following statistical tests were used: analysis of variance of Kruskal-Wallis test and post hoc multiple comparisons; Mann-Whitney U-test; Pearson's chi-squared test to assess the relationship between two categorical variables; and Spearman's correlation coefficients. For the purpose of showing the relationships between the values of PCS and MCS as the dependent variables and independent variables (IADL, ADL, GDS, MMSE, age, and sex), the analysis of covariance was performed. The influence of the independent variables on the dependent variables was estimated, and the determination coefficient was determined to explain the variability of the variable PCS or MCS (in percentages) in the covariance model used in the study. The statistical significance level was established at $P<0.05$.

\section{Results}

Table 1 contains demographic characteristics. The average age of care receivers in group II was significantly lower than in other groups $(P<0.001)$. Study participants assessed their health condition as good or bad, with the following respective results: in group I $-39 \%$ and $61 \%$ of residents; in group II $-56 \%$ and $44 \%$ of care receivers; and in group III $-14 \%$ and $86 \%$ of subjects (Table 1). In the aforementioned category, group III subjects significantly differed from those of group I and II $(P<0.001)$, whereas the significance of differences between groups II and I was at $P<0.05$. In all of the subjects, the prevalence of at least one of the following diseases was demonstrated: diabetes mellitus, hypertension, coronary heart disease, cardiac arrhythmias, heart failure, chronic disease of respiratory tract, rheumatics,

Table I General characteristics of investigated persons

\begin{tabular}{|c|c|c|c|c|}
\hline \multirow[t]{2}{*}{ Parameter } & \multirow[t]{2}{*}{ Scale range } & \multicolumn{3}{|l|}{ Investigated groups } \\
\hline & & $\begin{array}{l}\text { Group I } \\
\text { (institutional long-term care) } \\
(n=I 00)\end{array}$ & $\begin{array}{l}\text { Group II } \\
\text { (institutional day care } \\
\text { and in-home care) } \\
(n=100)\end{array}$ & $\begin{array}{l}\text { Group III } \\
\text { (in-home care) } \\
(n=100)\end{array}$ \\
\hline \multirow[t]{2}{*}{ Sex } & Male & 45 & 40 & 37 \\
\hline & Female & 55 & 60 & 63 \\
\hline $\begin{array}{l}\text { Age (yr), mean; median } \\
\text { (interquartile range) }\end{array}$ & & $\begin{array}{l}77.2 ; \\
76(65-95)\end{array}$ & $\begin{array}{l}\text { 7I.8; } \\
71(65-93)^{\dagger}\end{array}$ & $\begin{array}{l}77.0 \\
76(65-92)\end{array}$ \\
\hline \multirow[t]{2}{*}{ Marital status } & Single & 97 & 91 & 97 \\
\hline & Married & 3 & 9 & 3 \\
\hline Living alone & & 0 & 82 & 81 \\
\hline \multirow[t]{2}{*}{ Education } & $\leq 10$ years $^{\mathrm{a}}$ & 66 & 62 & 72 \\
\hline & $>10$ years $^{\mathrm{b}}$ & 34 & 38 & 28 \\
\hline Personal perception & Good & 39 & $56^{*}$ & $14^{\ddagger}$ \\
\hline of the state of health & Bad & 61 & 44 & 86 \\
\hline \multirow[t]{2}{*}{ Comorbidities $^{c}$} & $\mathrm{I}-2$ & 32 & 26 & 17 \\
\hline & $\geq 3$ & 68 & 74 & $83 *$ \\
\hline
\end{tabular}

Notes: a Primary and secondary level. ${ }^{b} \mathrm{High}$ school and higher education. ${ }^{\mathrm{c} D i a b e t e s ~ m e l l i t u s, ~ h y p e r t e n s i o n, ~ c o r o n a r y ~ h e a r t ~ d i s e a s e, ~ c a r d i a c ~ a r r h y t h m i a s, ~ h e a r t ~ f a i l u r e, ~ c h r o n i c ~}$ disease of respiratory tract, rheumatics, or neoplasms. ${ }^{\dagger} P<0.00$ I versus groups I and III; $\neq P<0.00$ I versus groups I and II; $* P<0.05$ versus group I. 
or neoplasms (Table 1). The co-occurrence of three or more of those diseases was most frequent in group III, which significantly differed it from group I $(P<0.05)$.

The analysis of the differences in scores revealed that community-dwelling elderly subjects (group III) had significantly lower health-status scores in all SF-36 domains compared to group I and group II $(P<0.001$; Table 2$)$. The health-status scores were similar between group I and group II, except for the physical functioning score which was the highest in group II, and the role emotional and mental component summary scores which were the highest in group I (Table 2). The analysis of the scores according to sex revealed that in the majority of the health-status dimensions, women had similar outcomes to men, except for the physical functioning scores in group I in which male individuals obtained significantly higher scores than females $(P<0.001)$.

Self-reported limitations in performing ADL were found mainly among community-based elderly people (group III), whereas group II subjects were mostly independent in ADL. Most frequently, individuals in group III required help performing ADL with regard to bathing (71\% subjects), dressing (50\%), toileting and transferring $(40 \%)$, and feeding $(21 \%)$. Urine or stool incontinence was reported by $64 \%$ of individuals. Institutionalized subjects reported difficulties in performing many ADL independently; however, this was to a lesser extent than subjects in group III. In group I, only $4 \%$ of individuals reported being unable to feed independently. In this group, more than $50 \%$ of subjects needed help in bathing. Fortyone percent of subjects required help in dressing and had difficulties with urinary bladder control. More than $30 \%$ required help in toileting and required a complete transfer from bed to chair. The highest independence in ADL was observed among group II, a few patients were dependent on others in performing ADL. Nevertheless, almost half of the subjects in this group reported partial or total incontinence of urine or stool.

Between-group comparison regarding sex revealed that women obtained slightly lower scores in ADL than men; however, the differences were not significant.

No significant differences in ADL were observed in groups I and II with reference to education level. However, the lowest scores were obtained by group III individuals with elementary and vocational education compared to highereducated subjects.

The assessment of IADL revealed the highest scores among group II individuals and the lowest scores among group III individuals. The differences between all groups were found to be statistically significant $(P<0.001$; Table 2). Nonetheless, subjects in group II were younger than individuals in other groups. The elderly receiving long-term care (group I) needed help with IADL with regard to shopping and doing housework (maintaining house, performing basic daily tasks, laundry); more than half of the subjects were fully dependent on others in performing these activities. Group II individuals were relatively independent in performing IADL. In this group, the subjects reported difficulties in doing housework. The majority of community-based subjects (group III) reported difficulties in performing most of the IADL on their own, ranging from using the telephone to handling personal finances. Seventy percent of subjects in group III were completely dependent on others in the following IADL: shopping, meal preparation, and doing housework.

The analysis of self-rated depressive symptoms with the use of the 30-item GDS found much-higher prevalence of depression among the elderly in the community (group III) when compared to group I and II subjects $(P<0.001$; Table 2). The prevalence of depression in group III was $78 \%$. In groups I and II, the prevalence of depression was $47 \%$ and $48 \%$, respectively. Factors like sex and education level were not found to be significantly associated with depression.

The highest MMSE scores were observed in group II individuals when compared to groups I and III (Table 2). The differences were statistically significant $(P<0.001)$. Dementia, recognized according to the MMSE criteria, was significantly more severe in individuals in groups I and III compared to those in group II. The scores for cognitive function were comparable between men and women in all three groups and they were positively associated with education level, although statistical significance was found only in group III $(P<0.05)$.

Table 3 presents correlations between health-status scores and other measures across all groups. Each assessed domain of the health status was strongly correlated with severity of depressive disorders in almost all groups. Cognitive impairment was strongly associated with a decline in ADL and increased severity of depressive symptoms; the associations were particularly strong in elderly subjects in groups I and III. Loss of independency in ADL was found to be strongly associated with a decline in domains of health status such as physical functioning, role physical, and general health in each of the assessed groups.

The model of covariance analysis used in the study including PCS and MCS as the dependent variables and IADL, ADL, GDS, MMSE, age, and sex as the dependent variables - appeared to be statistically significant $(P<0.001)$. 


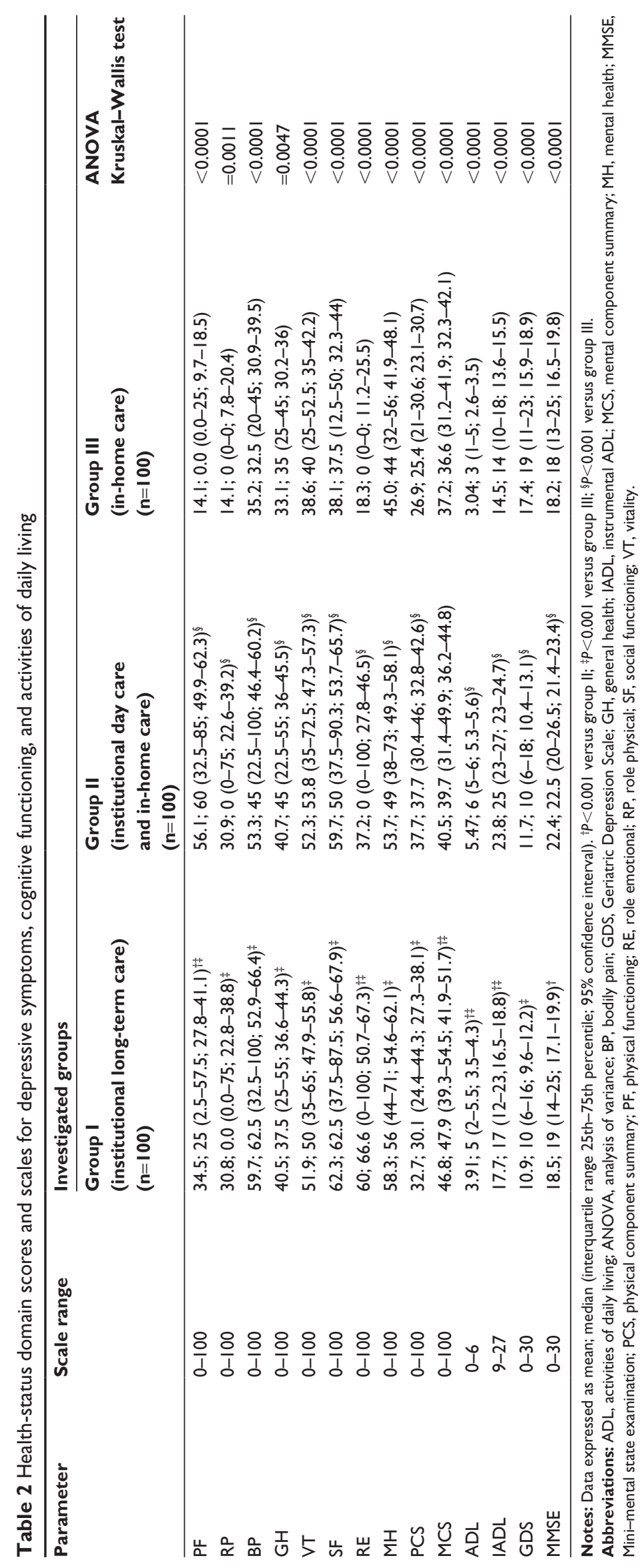


Table 3 Correlation coefficients $(r)$ of between-group comparison of the health-status domain scores as well as ADL, cognitive functioning, and depression scales

\begin{tabular}{|c|c|c|c|c|}
\hline \multirow{2}{*}{\multicolumn{2}{|c|}{ Correlated indices }} & \multirow{2}{*}{\multicolumn{3}{|c|}{ Investigated groups }} \\
\hline & & & & \\
\hline \multirow{4}{*}{$\mathrm{PF}$} & $\mathrm{ADL}$ & $0.58^{\dagger}$ & $0.36^{\dagger}$ & $0.57^{\dagger}$ \\
\hline & IADL & $0.49^{\dagger}$ & $0.50^{+}$ & $0.5 \mathrm{I}^{\dagger}$ \\
\hline & MMSE & 0.02 & 0.12 & $0.27^{*}$ \\
\hline & GDS & 0.08 & $-0.45^{\dagger}$ & $-0.50^{\dagger}$ \\
\hline \multirow[t]{4}{*}{$\mathrm{RP}$} & ADL & $0.45^{\dagger}$ & 0.09 & $0.27^{*}$ \\
\hline & IADL & $0.45^{\dagger}$ & $0.21 *$ & $0.3 I^{\ddagger}$ \\
\hline & MMSE & $0.20 *$ & 0.11 & 0.04 \\
\hline & GDS & -0.07 & $-0.3 I^{\ddagger}$ & $-0.34^{\dagger}$ \\
\hline \multirow[t]{4}{*}{ BP } & $A D L$ & 0.08 & 0.18 & $0.29^{\ddagger}$ \\
\hline & IADL & -0.1 & 0.1 & 0.16 \\
\hline & MMSE & -0.08 & -0.19 & 0.11 \\
\hline & GDS & $-0.34^{\dagger}$ & $-0.31^{\ddagger}$ & $-0.23 *$ \\
\hline \multirow[t]{4}{*}{$\mathrm{GH}$} & $A D L$ & $0.22^{*}$ & $0.20 *$ & $0.30^{\ddagger}$ \\
\hline & IADL & $0.22 *$ & $0.21 *$ & $0.25 *$ \\
\hline & MMSE & 0.09 & -0.04 & 0.10 \\
\hline & GDS & $-0.47^{\dagger}$ & $-0.46^{\dagger}$ & $-0.38^{\dagger}$ \\
\hline \multirow[t]{4}{*}{ VT } & $A D L$ & -0.03 & $0.25^{\ddagger}$ & $0.20 *$ \\
\hline & IADL & 0.02 & $0.20 *$ & $0.22^{*}$ \\
\hline & MMSE & -0.03 & -0.01 & 0.14 \\
\hline & GDS & $-0.57^{\dagger}$ & $-0.56^{\dagger}$ & $-0.38^{\dagger}$ \\
\hline \multirow[t]{4}{*}{ SF } & $A D L$ & $0.21^{*}$ & 0.18 & $0.27^{\ddagger}$ \\
\hline & IADL & 0.18 & 0.18 & $0.37^{\dagger}$ \\
\hline & MMSE & $0.23^{*}$ & -0.07 & 0.15 \\
\hline & GDS & $-0.42^{\dagger}$ & $-0.5 \mathrm{I}^{\dagger}$ & $-0.39 \dagger$ \\
\hline \multirow[t]{4}{*}{ RE } & ADL & 0.01 & 0.18 & $0.35^{\dagger}$ \\
\hline & IADL & 0.10 & $0.34^{\dagger}$ & $0.35^{\dagger}$ \\
\hline & MMSE & 0.03 & 0.10 & $0.37^{\dagger}$ \\
\hline & GDS & -0.16 & $-0.42^{\dagger}$ & $-0.43^{\dagger}$ \\
\hline \multirow[t]{4}{*}{$\mathrm{MH}$} & $A D L$ & -0.05 & $0.25^{*}$ & 0.16 \\
\hline & IADL & -0.06 & 0.16 & 0.16 \\
\hline & MMSE & 0.02 & -0.13 & 0.15 \\
\hline & GDS & $-0.58^{\dagger}$ & $-0.65^{\dagger}$ & $-0.36^{\dagger}$ \\
\hline \multirow[t]{4}{*}{ PCS } & $A D L$ & $0.5 \mathrm{I}^{\dagger}$ & $0.3^{\ddagger}$ & $0.4^{\dagger}$ \\
\hline & IADL & $0.39^{\dagger}$ & $0.26^{\ddagger}$ & $0.43^{\dagger}$ \\
\hline & MMSE & $0.21 *$ & $0.28^{\ddagger}$ & $0.35^{\ddagger}$ \\
\hline & GDS & -0.16 & $-0.35^{\dagger}$ & $-0.34^{\ddagger}$ \\
\hline \multirow[t]{4}{*}{ MCS } & ADL & $0.22 *$ & $0.2^{*}$ & 0.18 \\
\hline & IADL & -0.07 & 0.19 & $0.27^{*}$ \\
\hline & MMSE & $0.48^{\dagger}$ & $0.6 \mathrm{I}^{\dagger}$ & $0.52^{\dagger}$ \\
\hline & GDS & $-0.48^{\dagger}$ & $-0.62^{\dagger}$ & $-0.52^{\dagger}$ \\
\hline \multirow[t]{3}{*}{ MMSE } & ADL & $0.33^{\dagger}$ & 0.06 & $0.47^{\dagger}$ \\
\hline & IADL & $0.31^{\ddagger}$ & $0.32^{\dagger}$ & $0.58^{\dagger}$ \\
\hline & GDS & $-0.22^{*}$ & 0.01 & $-0.44^{\dagger}$ \\
\hline \multirow[t]{2}{*}{ GDS } & $\mathrm{ADL}$ & -0.04 & $-0.34^{\dagger}$ & $-0.60^{\dagger}$ \\
\hline & IADL & -0.09 & $-0.24^{*}$ & $-0.58^{\dagger}$ \\
\hline$A D L$ & IADL & $0.53^{\dagger}$ & $0.24^{*}$ & $0.72^{\dagger}$ \\
\hline
\end{tabular}

Notes: $* P<0.05 ; ¥ P<0.01 ;+P<0.001$.

Abbreviations: ADL, activities of daily living; BP, bodily pain; GDS, Geriatric Depression Scale; GH, general health; IADL, instrumental ADL; MCS, mental component summary; MH, mental health; MMSE, Mini-mental state examination; PCS, physical component summary; PF, physical functioning; RE, role emotional; RP, role physical; $\mathrm{SF}$, social functioning; VT, vitality. 
The calculated determination coefficients $R^{2}$ indicate that this model explains over $39 \%$ of the variance of the variable PCS $\left(R=0.62 ; R^{2}=0.39 ; F=17.79 ; P<0.001\right)$ and over $52 \%$ of the variance of the variable $\operatorname{MCS}\left(R=0.72 ; R^{2}=0.52 ; F=30.02\right.$; $P<0.001)$.

Neither of the investigated dimensions of health status showed a significant correlation with the age of participants (Table 4). The significant negative correlation between age, the level of cognitive function, and IADL was observed among subjects in group I.

\section{Discussion}

The present study investigated health aspects in the elderly population of southern Poland using the SF-36 and analyzed the associations in sociodemographic characteristics. According to our findings, the health aspects of the elderly population is varied and is related to the setting in which care is provided, ie, whether the provision of care is in clinical or home environments. Specifically, better health aspects were found in the residents of long-term care facilities and day-care homes than in the elderly at their place of residence. It might be related to the fact that senior people staying in institutionalized settings had a sense of personal security and stability. After a long stay, the elderly residents adapted to the surroundings, and socialized and interacted with other residents and the personnel. Moreover, in these facilities, nursing assistance, medical consultations, and adequate treatment were ensured. Consequently, these individuals were more likely to express satisfaction with their general health and increased feelings of well-being. As shown by our observations, the care provided by adult day-care homes was a beneficial solution for the elderly living on their own. These persons were coming to adult day-care homes in the morning hours and staying there till the afternoon. They had all their meals provided, they were meeting their peers, doing some physical exercises, relaxing by listening to their favorite music, taking part in group and individual activities, praying together, and singing. Furthermore, psychological support and rehabilitation, as well as social care, was provided. Care receivers using this form of care were better at ADL, IADL, and cognitive function than group I and III subjects, which might be also related to their younger age.

In contrast, the lowest health aspects were found among the elderly individuals residing at home which was rather puzzling, since it was predicted that staying in a familiar setting ought to have a more beneficial effect on the elderly's well-being rather than residing in long-term care institutions. It is presumed that the exhibition of low-health aspects by this group of the elderly is related to numerous factors. Firstly, lower health aspects of the community-dwelling elderly is associated with

Table 4 Correlation coefficients $(r)$ of between-group comparison of the age and health status domain scores, as well as the ADL, cognitive functioning, and depression scales

\begin{tabular}{|c|c|c|c|c|}
\hline \multicolumn{2}{|c|}{ Correlated indices } & \multicolumn{3}{|l|}{ Investigated groups } \\
\hline & & $\begin{array}{l}\text { Group I } \\
\text { (institutional long-term care) } \\
(\mathrm{n}=\mid \mathbf{0 0})\end{array}$ & $\begin{array}{l}\text { Group II } \\
\text { (institutional day care } \\
\text { and in-home care) } \\
(n=100)\end{array}$ & $\begin{array}{l}\text { Group III } \\
\text { (in-home care) } \\
(\mathrm{n}=100)\end{array}$ \\
\hline \multirow[t]{14}{*}{ Age } & PF & -0.01 & -0.08 & 0.01 \\
\hline & $\mathrm{RP}$ & -0.11 & -0.09 & 0.15 \\
\hline & $\mathrm{BP}$ & -0.02 & 0.07 & 0.01 \\
\hline & $\mathrm{GH}$ & 0.07 & 0.08 & 0.12 \\
\hline & VT & -0.15 & -0.08 & 0.14 \\
\hline & SF & -0.04 & 0.10 & 0.12 \\
\hline & RE & 0.02 & 0.01 & -0.01 \\
\hline & $\mathrm{MH}$ & -0.01 & 0.11 & 0.17 \\
\hline & PCS & -0.07 & -0.02 & 0.09 \\
\hline & MCS & -0.004 & 0.1 & 0.15 \\
\hline & $A D L$ & -0.19 & -0.10 & -0.01 \\
\hline & IADL & $-0.23 *$ & -0.14 & -0.12 \\
\hline & MMSE & $-0.34^{\dagger}$ & $-0.3 I^{\ddagger}$ & -0.13 \\
\hline & GDS & $0.22^{*}$ & -0.13 & -0.02 \\
\hline
\end{tabular}

Notes: $* P<0.05 ; ¥ P<0.01 ;{ }^{\dagger} P<0.001$.

Abbreviations: ADL, activities of daily living; BP, bodily pain; GDS, Geriatric Depression Scale; GH, general health; IADL, instrumental ADL; MCS, mental component summary; MH, mental health; MMSE, Mini-mental state examination; PCS, physical component summary; PF, physical functioning; RE, role emotional; RP, role physical; SF, social functioning; VT, vitality. 
the prevalence of negative feelings of loneliness and isolation. Those feelings, frequently in association with the presence of general medical illnesses, significantly influence their respective health aspects. Our study showed that $82 \%$ of the patients that lived alone and the findings revealed that loneliness was more frequently reported by single individuals. The absence of a spouse or immediate family creates insecurity and isolation. Moreover, loneliness in the elderly is the effect of lack of confidence, lack of meaning in life, lack of social support, social inactivity, and sadness. It should also be noted that persons staying in the home environment more-frequently suffered from numerous diseases and declared worse health conditions than care receivers in other comparable groups. It can be assumed that persons admitted to residential care homes and even more frequently to adult day-care homes were of better general health than those staying in home care.

All these feelings have enormous implications on health aspects and may lead to the development of depressive disorders. Furthermore, poor-health aspects among elderly residing in their own homes, as it has been observed in our study, were related to significant limitations in performing basic and more advanced ADL as well as impaired cognitive functioning. Considering these issues, our results are in agreement with other studies. Noro and $\mathrm{Aro}^{17}$ in their study, compared health and functional ability between noninstitutionalized and institutionalized elderly in Finland. The study cohort consisted of 475 elderly subjects living at home and 459 patients in residential care. Home-dwellers partially dependent on others for ADLs assessed their health as being significantly worse than the elderly living in residential homes. Noninstitutionalized elderly needing some help with ADL were found to have feelings of social isolation and loneliness, and were less able to manage in-home care than those in residential care. ${ }^{17}$ It was also observed that health status of the after-stroke elderly in a nursing home was significantly higher than that of their peers living in their own home, which may be related to better care in specially organized settings. ${ }^{18}$

Poorer overall health status of the noninstitutionalized elderly might be related to an inadequate duration of inhome care provision. Nursing care services were found to be provided on an hourly basis (maximally 3 hours daily) which was insufficient to meet specific care needs of these individuals. Furthermore, a lower economic status of the majority of community-dwelling individuals had a major impact on their assessment of care. More than 50\% of subjects had insufficient financial means to pay the cost of additional assistance in terms of extended time or widened scope of caring and nursing services. Yet, a vast majority of elderly persons living in the community reported a high level of satisfaction with the quality of care provided by their caregivers. Still, more than $50 \%$ of subjects reported that the length of time and scope of care services were insufficient to meet their needs.

Sociodemographic variables measured such characteristics as sex, education level, and age. With reference to sex, women obtained similar scores to men in all domains except for the physical functioning scale, in which male inhabitants of residential homes showed significantly higher scores than females. The scores for the health status in the remaining domains did not differ between sexes. Regarding the scores for education level, the differences were nonsignificant. Thus, no influence from years of education on health status was detected in the present study. Other studies in relation to this variable showed similar results. Grzegorczyk and Kwolek, ${ }^{19}$ in the study on self-rated health of elderly residents of nursing homes in Subcarpathian Voivodship of Poland using the Nottingham Health Profile scale, found no significant differences with respect to education level. Nonetheless, these findings differ from other studies on health status of the Polish elderly population, which found associations between education level and health status. Specifically, higher educated elderly reported a better selfassessment of health. This may be attributed to possessing more extensive knowledge and leading a more-healthy lifestyle. ${ }^{5}$ Yet, those studies investigated the general elderly population rather than the elderly individuals in care, which affected the results considerably.

In analyzing health status with regard to age, no correlations were found in all scales between the groups in the present study, which is consistent with other studies. Borowiak and Barylska ${ }^{20}$ in the study of elderly residents of nursing homes also found no significant associations between sex, age, and health status. Nonetheless, some studies investigating the general population of the elderly in Poland revealed an inverse correlation with age. Specifically, the advance in age was associated with lower health status. Marcinowicz and Sienkiewicz, ${ }^{21}$ in their study evaluating self-reported health status with the SF-36 questionnaire in 1,000 randomly selected patients of a wide age range (only one in five subjects was 65 years old and above), observed an association between these domains. Substantially, the deterioration of health status with advancing age was attributed to a decline in functional and cognitive health in the oldest elderly and with the prevalence of depressive symptoms in individuals at more advanced age. ${ }^{22}$ 
In the present study, it was found that severity of depression was significantly correlated with self-assessed general health status in both community and institutionalized elderly individuals, suggesting that depressive disorders were strongly associated with a lower health status in the elderly. Borowiak and Kostka ${ }^{23}$ showed that depression was the most powerful predictor of health status in community and institutionalized elderly.

Furthermore, our study revealed associations between ADL scores, IADL scores, and self-rated health status in the elderly. Specifically, in the institutionalized elderly, dependence on others for ADL was positively related to poorer scores in multiple domains of health status, and in community-dwelling subjects, dependence on others for ADL was positively related to low scores in almost all domains of health status. A decline in ADL function was significantly linked to reduced health status in the following domains: physical functioning, role physical, general health, and vitality.

Regarding cognitive status, as assessed with the MMSE, we have found lower ADL scores in the elderly with increased severity of cognitive disorders in all groups, which suggests that being functionally dependent on others for ADL is clearly associated with a cognitive decline. Similar results have been found in other studies. Sosnowski and ChmaraPawlinska, ${ }^{24}$ who investigated a sample of 79 elderly persons with cognitive disorders grouped according to the causes of impairment into Alzheimer's disease group, vascular dementia group, and mixed-dementia group, observed strong correlations between the severity of cognitive impairment measured by the MMSE and functional disability in ADL items. Mathuranath et $\mathrm{al}^{25}$ in a study investigating 240 patients divided into a cognitively impaired group and a control group, found a significant correlation between IADL dependence and impaired cognitive capacity.

The main limitation of our study was related to the difficulties in filling out the self-administered questionnaires by the elderly, whose impaired vision, cognitive-function decline, and medical conditions, which were particularly significant in persons in home care, might have negatively affected the quality of the obtained scores. However, the abovementioned limitation was decreased due to the fact that all the questionnaires were filled in with the assistance of the same researcher. Another limitation of the study in the comparative analysis was the fact that the examined persons in the groups were incomparable in terms of age (the persons in adult day-care homes were younger on average), in terms of the duration of loneliness, and in terms of the number of accompanying diseases (over $80 \%$ of persons who were provided with in-home care were alone for about 20 hours daily and suffered from at least three chronic diseases).

\section{Conclusion}

In conclusion, this study showed that the physical and mental health aspects of the elderly in Poland are related to the type of care provision. The elderly in long-term institutionalized care, both in a residential home and in adult day-care homes, were characterized by a better physical and mental health status than those receiving in-home care. It seems that worse health status, including more-frequent depression occurrence and cognitive-function disorders, in the elderly using nursing care at their homes is related to their multimorbidity, loneliness, and too-short duration of the care during the day.

\section{Disclosure}

The authors report no conflicts of interest in this work.

\section{References}

1. Harman D. Aging: overview. An N Y Acad Sci. 2001;928:1-21.

2. Crimmins EM. Trends in the health of the elderly. Annu Rev Public Health. 2004;25:79-98.

3. Vladeck BC. Economic and policy implications of improving longevity. $J$ Am Geriatr Soc. 2005;53(9 Suppl):S304-S307.

4. Freedman VA, Crimmins E, Schoeni RF, et al. Resolving inconsistencies in trends in old-age disability: report from a technical working group. Demography. 2004;41(3):417-441.

5. Barcikowska M, Czlonkowska A, Derejczyk J, et al. Public health problems in the context of ageing of the population of Poland. Report. Postepy Psychiatrii i Neurologii. 2006;15(3):203-211.

6. Barca ML, Engedal K, Laks J, Selbæk G. Quality of life among elderly patients with dementia in institutions. Dement Geriatr Cogn Disord. 2011;31(6):435-442.

7. De Luca d'Alessandro E, Bonacci S, Giraldi G. Aging populations: the health and quality of life of the elderly. Clin Ter. 2011;162(1):13-18.

8. Kostka T, Jachimowicz V. Relationship of quality of life to dispositional optimism, health locus of control and self-efficacy in older subjects living in different environments. Qual Life Res. 2010;19(3):351-361.

9. Noro A, Aro S. Health-related quality of life among the least dependent institutional elderly compared with the non-institutional elderly population. Qual Life Res. 1996;5(3):355-366.

10. Reimer MA, Slaughter S, Donaldson C, Currie G, Eliasziw M. Special care facility compared with traditional environments for dementia care: a longitudinal study of quality of life. J Am Geriatr Soc. 2004; 52(7):1085-1092.

11. Ware J. SF-36 health survey update. Spine (Phila Pa 1976). 2000; 25(24):3130-3139.

12. Katz S, Ford AB, Moskovitz RW, Jackson BA, Jaffe MW. Studies of illness in the aged. The index of ADL: a standardized measure of biological and psychosocial function. JAMA. 1963;185:914-919.

13. Lawton MP. Quality of life in Alzheimer disease. Alzheimer Dis Assoc Disord. 1994;8 Suppl 3:138-150.

14. Yesavage JA, Brink TL, Rose TL, et al. Development and validation of a geriatric depression screening scale: a preliminary report. J Psychiatr Res. 1982-1983;17(1):37-49.

15. Folstein MF, Folstein SE, McHugh PR. "Mini-Mental State". A practical method for grading the cognitive state of patients for the clinician. J Psychiatr Res. 1975;12(3):189-198. 
16. Bland JM, Altman DG. Cronbach's alpha. BMJ. 1997;314:572.

17. Noro A, Aro S. Comparison of health and functional ability between noninstitutionalized and least dependent institutionalized elderly in Finland. Gerontologist. 1997;37(3):374-383.

18. Brajković L, Godan A, Godan L. Quality of life after stroke in old age: comparison of persons living in nursing home and those living in their own home. Croat Med J. 2009;50:182-188.

19. Grzegorczyk JM, Kwolek A. [Factors determining the quality of life of residents in homes for the aged - preliminary report]. Wiad Lek. 2002; 55 Suppl 1:108-113. Polish.

20. Borowiak E, Barylska A. Problems of seniors in House of Day's Staychallenge for nurse. Probl Pielegn. 2007;15(1):13-19.

21. Marcinowicz L, Sienkiewicz J. [Assessment of the validity and reliability of the Polish version of the SF-36 questionnaire - preliminary findings]. Przegl Lek. 2003;60 Suppl 6:103-106.
22. Sullivan MD, Kempen GI, Van Sonderen E, Ormel J. Models of healthrelated quality of life in a population of community-dwelling Dutch elderly. Qual Life Res. 2000;9(7):801-810.

23. Borowiak E, Kostka T. Predictors of quality of life in older people living at home and in instytutions. Aging Clin Exp Res. 2004;16(3): 212-220.

24. Sosnowski M, Chmara-Pawlińska R. [An assessment of functions of ADL Index and MMSE in patients with various demention syndroms of different origin]. Medycyna Rodzinna. 2002;5:176-178.

25. Mathuranath PS, George A, Cherian PJ, Mathew R, Sarma PS. Instrumental activities of daily living scale for dementia screening in elderly people. Int Psychogeriatr. 2005;17(3):461-474.
Clinical Interventions in Aging

\section{Publish your work in this journal}

Clinical Interventions in Aging is an international, peer-reviewed journal focusing on evidence-based reports on the value or lack thereof of treatments intended to prevent or delay the onset of maladaptive correlates of aging in human beings. This journal is indexed on PubMed Central, MedLine,

\section{Dovepress}

CAS, Scopus and the Elsevier Bibliographic databases. The manuscript management system is completely online and includes a very quick and fair peer-review system, which is all easy to use. Visit http://www.dovepress. com/testimonials.php to read real quotes from published authors. 